\title{
A Predictive Model of Different Temperature Growth of Escherichia Coli in Fresh- cut Lettuce Based on Matlab7.0
}

\author{
HuiXia Duan, Feng Tan*, Xinxin Yi, Hongxing Zhang, Maoshu Hou, James E. M. Monaghan \\ Food Science and Engineering College, International College, \\ Beijing University of Agriculture, \\ Beijing, 102206, China \\ Harper Adams University, \\ Newport, Shropshire, TF10 8NB
}

\begin{abstract}
Contamination of Escherichia coli in fresh-cut lettuce poses potential risk to the public. In order to study the growth characteristics of Escherichia coli 1.1187, we established a prediction model of different temperature growth of Escherichia coli in fresh-cut lettuce based on Matlab7.0. In this study, the prediction model can well forecast the dynamic growth of Escherichia coli 1.1187 in fresh-cut lettuce, and it provides a rapid and effective method for safety assessment of fresh-cut lettuce during storage. The growth state of Escherichia coli 1.1187 was analyzed at different temperatures $\left(4^{\circ} \mathrm{C}, 11^{\circ} \mathrm{C}, 19^{\circ} \mathrm{C}, 27^{\circ} \mathrm{C}\right.$ and $\left.35^{\circ} \mathrm{C}\right)$. The primary prediction model was established by modified the Gompertz equation. The secondary prediction model was established by square root equation. Then the model was verified at different temperatures $\left(22^{\circ} \mathrm{C}\right.$ and $\left.30^{\circ} \mathrm{C}\right)$. Experimental results showed that the primary prediction model fitting correlation coefficient is above 0.99 , the bias factor and accuracy factor of secondary model are in the range of 0.90 and 1.05 . At $4^{\circ} \mathrm{C}$, Escherichia coli 1.1187 growth was restrained dramatically, so it is impossible for fitting by modified the Gompertz equation. In this study, we obtained the low growth temperature and the optimum growth temperature of E.coli 1.1187 were $7.03^{\circ} \mathrm{C}$ and $17.52^{\circ} \mathrm{C}$ respectively.
\end{abstract}

Keywords-predictive model; escherichia coli; fresh-cut Lettuce; Matlab7.0.

\section{INTRODUCTION}

One of the main factors that cause foodborne illness is pathogen contamination. National foodborne disease monitoring network statistics show that over the past decade, in the event of domestic foodborne diseases caused by microorganisms, Escherichia coli accounted for 5.6\%, so it is one of the main pathogens ${ }^{[1]}$. Fresh-cut lettuce maintaining the in vivo characteristics of fresh vegetables, but the cut lead to a deterioration of a series of physiological and biochemical reactions occur. In addition, due to the internal outflow of nutrients on the microbial provide a favorable living conditions, increase the types and quantities of microbial cross-contamination of fruits and vegetables, the internal organization has also been microbial infection. Internal and external factors affecting the growth of microorganisms in fresh-cut lettuce, temperature is one of the most important external factors.

Predict food microbiology is an important tool for managing food safety, its main research direction is to design a series of models to describe and predict the growth and survival of microorganisms under certain conditions. It built up a microbiology mathematical statistics and applied computer science on the basis of a new discipline ${ }^{[2]}$. It provides a scientific basis for quantitative microbiological risk assessment (QM-RA) and Critical Control Point Hazard Analysis (HACCP) ${ }^{[3]}$.

The objectives of this study were (i) to analysis the growth of Escherichia coli 1.1187(strain of Escherichia coli K12) under different temperature conditions, and (ii) under laboratory conditions, using the same inoculum at a constant temperature of $4^{\circ} \mathrm{C}, 11^{\circ} \mathrm{C}, 19^{\circ} \mathrm{C}, 27^{\circ} \mathrm{C}$ and $35^{\circ} \mathrm{C}$, to develop and validate a predictive model to predict Escherichia coli 1.1187 growth in fresh-cut lettuce over storage time based on Matlab7.0.

\section{MATERIALS AND METHODS}

\section{A. Materials}

Lettuce purchased from the northern suburb market in Beijing; Escherichia coli 1.1187 purchased from the Institute of Microbiology of the Chinese Academy of Sciences; Nutrient agar (NA) was purchased from Beijing Lanyi Chemical Co., Ltd..

\section{B. Methods}

1) Bacterial suspension and sample preparation

Preparation of the bacterial suspension: Escherichia coli 1.1187 on nutrient agar crossed activation, cultured $18 \mathrm{~h}$ at $37^{\circ} \mathrm{C}$, single colony was picked into a conical flask containing $100 \mathrm{~mL}$ of physiological saline to shake uniform;

Fresh lettuce - selection - remove the skin one or two layers - crushing juice - fresh lettuce juice - distribute into triangular flask - sterilization - sterile lettuce juice;

Inoculated with Escherichia coli 1.1187: suck up the quantitative bacterial suspension in accordance with the proportion of $1 \mathrm{~mL} / 100 \mathrm{~g}$ to inoculate into the sterile lettuce juice.

2) Bacterial culture and detection

Based on fruit and vegetable cold chain temperature and bacterial culture temperature, $4^{\circ} \mathrm{C}, 13^{\circ} \mathrm{C}, 21^{\circ} \mathrm{C}, 29^{\circ} \mathrm{C}$ and $37^{\circ} \mathrm{C}$ were selected as the constant culture temperature. The sterile lettuce juices after inoculated with E.coli 1.1187 were respectively bottled into $250 \mathrm{~mL}$ triangular flasks, and cultivate them under different temperature conditions. Every 
$12 \mathrm{~h}$ check once the total number of bacterias. Each trial fetch $1 \mathrm{~mL}$ of lettuce juices under different temperature conditions with the aseptic technique, and diluted to ten folds. Under each different temperature condition separately taken right gradient, by hybrid method pour it into the nutrient agar media which cooled to about $45^{\circ} \mathrm{C}$. Check the total number of bacterias after $48 \mathrm{~h}$ culture under $37^{\circ} \mathrm{C}$. Do 3 sets of parallel experiments for each sample, finally take the average of the counting results.

3) Colony counts method and data processing and analysis

Referencing the method of National Standard GB 4789.2-2010(Food microbiological testing determining bacterial colony number), count the colony of lettuce juices in $1 \mathrm{CFU} / \mathrm{g}$; The experimental datas are analyzed and plotted by Matlab 7.0 software $^{[4]}$.

4) Growth curve and the fitting of two order equations

The datas at different constant temperature are fitted with the modified Gompertz equation ${ }^{[5]}$ in order to describe the growth dynamics at different temperature. Kinetic parameters were calculated based on the growth curve, using (2) and (3) to fit the relationship between microbial growth rate and microbial growth delay time and temperature in order to describe the influence of temperature on the parameters of growth kinetics, then do nonlinear regression method using the least squares method by Matlab7.0 software.

Modified Gompertz model function expression:

$$
\log \left(N_{t}\right)=\log \left(N_{0}\right)+\log \left(\frac{N_{\max }}{N_{0}}\right) * \exp \left(-\exp \left(\frac{e * \mu_{\max }}{\log \left(\frac{N_{\max }}{N_{0}}\right)} *(\lambda-t)+1\right)\right)
$$

In the expression, $e=2.718281828459, t$ is the time (h), $N_{t}$ is the bacterial counts of microorganisms at time $t(\mathrm{cfu} / \mathrm{g})$, $\log \left(N_{\max } / N_{0}\right)$ is the difference of the logarithm of the maximum bacterial counts $\log \left(N_{\max }\right)$ in stable stage and the logarithm of the initial bacterial counts $\log \left(N_{0}\right), \lambda$ is lag phase (h) in Microbiology sense, $\mu_{\max }$ is the maximum specific growth rate of microorganisms $\left(\mathrm{h}^{-1}\right)$.

This is a nonlinear microbial growth model. The microorganism quantities $\mathrm{N}$ of at different time $\mathrm{t}$ and different conditions in the experiment are fitted respectively by the equations, in order to find the four parameters, namely $\log \left(N_{0}\right), \log \left(N_{\max }\right), \log \left(N_{\max } / N_{0}\right)$ and $\mu_{\max }$.

The model of square root is the major model used to describe the impact of environmental factors, the simple expression:

$$
\begin{gathered}
\sqrt{U}=b\left(T-T_{\min }\right) \\
\sqrt{\mu_{\max }}=b_{1}\left(T-T_{\min }\right)
\end{gathered}
$$

$$
\sqrt{1 / \lambda}=b_{2}\left(T-T_{\min }\right)
$$

Where $\lambda$ is lag phase (h) in Microbiology sense, $b_{1}$ and $b_{2}$ are coefficients $\left({ }^{\circ} \mathrm{C}^{-1} \mathrm{~h}^{-0.5}\right), \mathrm{T}$ is the culture temperature $\left({ }^{\circ} \mathrm{C}\right), \mu_{\max }$ is the maximum specific growth rate of microorganisms $\left(\mathrm{h}^{-1}\right), T_{\min }$ is a hypothetical concept and refers to the temperature at which microorganism is no metabolic activity. $T_{\min }$ is the temperature at which is obtained by intersecting the extrapolation regression line and temperature axis.

5) Model Validation

By the comparison of measurement datas under $22^{\circ} \mathrm{C}$ and $30^{\circ} \mathrm{C}$ storage conditions and forecast datas of the model, Bias factor $\left(B_{f}\right)$ and Accuracy factor $\left(A_{f}\right)$ are calculated with (5) and (6) to validate the reliability of the model. Bias factor $\left(B_{f}\right)$ is used to measure the fluctuations up and down the range, Accuracy factor $\left(A_{f}\right)$ is used to measure the difference between the predicted and measured datas. When the caculated results is 1.0 , which means that the predicted value has no error, when the caculated results is 1.1 and 0.9 , which means that the predicted has respectively error of $10 \%$ up and down. Meanwhile the square of the correlation coefficient $\left(\mathrm{R}^{2}\right)$ between the predicted and measured values can be used to determine the accuracy between the predicted and measured values.

Bias factor and Accuracy factor are expressed by the following formula:

Bias factor:

$$
B_{f}=10^{\frac{\sum \log \left(\frac{N_{p r d}}{N_{o b s}}\right)}{n}}
$$

Accuracy factor:

$$
A_{f}=10 \frac{\sum\left|\log \left(\frac{N_{p r d}}{N_{o b s}}\right)\right|}{n}
$$

Where Nprd is forecast value, Nobs is the measured value, $\mathrm{n}$ is the time of experiments. When Bias factor and accuracy factor are:

- 0.90-1.05, the model has high precision and with little error.

- $0.70-0.90$ or $1.06-1.15$, the precision of the model can be accepted, but the error is larger.

- $<0.70$ or $>1.15$, the model is unreliable, so it cannot be used to simulate to describe the growth of microorganisms ${ }^{[6]}$.

\section{RESULTS AND ANALYSIS}

\section{A. Growth curve for Escherichia coli 1.1187 in different constant temperature}

The sterile lettuce juices were inoculated with Escherichia coli 1.1187 , the initial bacteria are all $6.0 \times 102$ 
$\mathrm{cfu} / \mathrm{g}$, and were placed in $4^{\circ} \mathrm{C}, 11^{\circ} \mathrm{C}, 19^{\circ} \mathrm{C}, 27^{\circ} \mathrm{C}$ and $35^{\circ} \mathrm{C}$ conditions separately, every $12 \mathrm{~h}$ check the total bacterias counts, its growth curve as shows in Fig. 1.

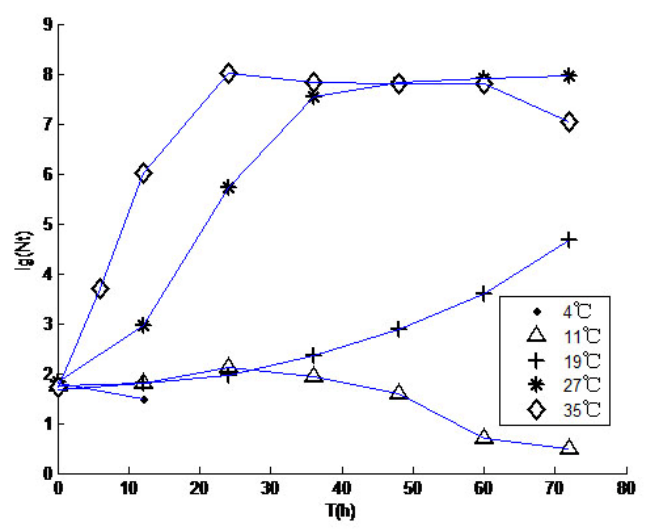

Fig.1. Escherichia coli 1.1187 growth curve under different constant temperature

\section{B. The fitting of the primary prediction model}

Using Matlab7.0 software to process the data of the bacteria counts which were measured in the stored sterile lettuce juices were inoculated with Escherichia coli 1.1187 under different temperature conditions by the method of nonlinear regression, to get the growth characteristic parameters of the modified Gompertz equation as in Table 1.

TABLE 1: KINETIC GROWTH PARAMETERS OF ESCHERICHIA COLI 1.1187 IN FRESH-CUT LETTUCE AT DIFFERENT TEMPERATURES

\begin{tabular}{|c|c|c|c|c|c|}
\hline \multirow{2}{*}{$\begin{array}{c}\text { Temperature } \\
\left({ }^{\circ} \mathrm{C}\right)\end{array}$} & \multicolumn{4}{|c|}{ Growth characteristic parameters } & Correlation coefficient \\
\cline { 2 - 5 } $\mathrm{R}^{2}$
\end{tabular}

Fig. 2 shows the data of the bacteria counts which were measured in the stored sterile lettuce juices were inoculated with Escherichia coli 1.1187 under $13^{\circ} \mathrm{C}, 21^{\circ} \mathrm{C}, 29^{\circ} \mathrm{C}$ and $37^{\circ} \mathrm{C}$ conditions. According to the measured data, the growth model of Escherichia coli 1.1187 under different temperature conditions is established by the modified Gompertz equation using the least-square linear fitting, as follows:
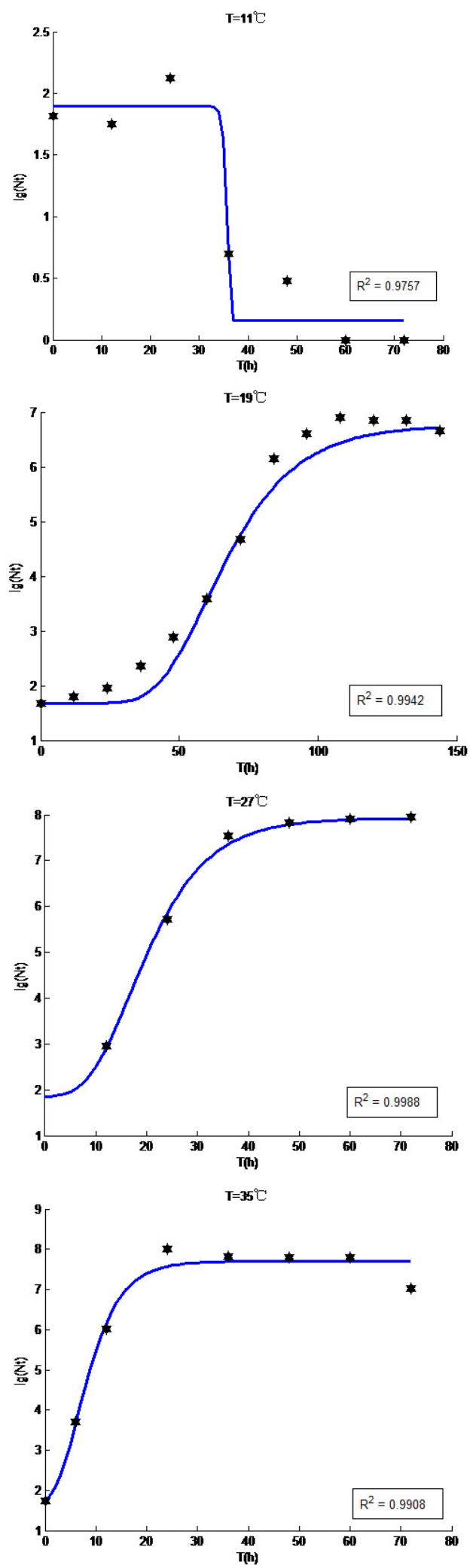

Fig.2. Fitted growth curves of Escherichia coli 1.1187 in fresh-cut Lettuce juice at different temperatures 


\section{The fitting of the secondary prediction model}

Using Matlab7.0 software to analysis the effects of temperature on the growth characteristic parameters of Escherichia coli 1.1187 in the sterile lettuce juices, to establish the square root equation[7]. The relationship of temperature with $\mu \max$ and $1 / \lambda$ were shown in Fig. 3.
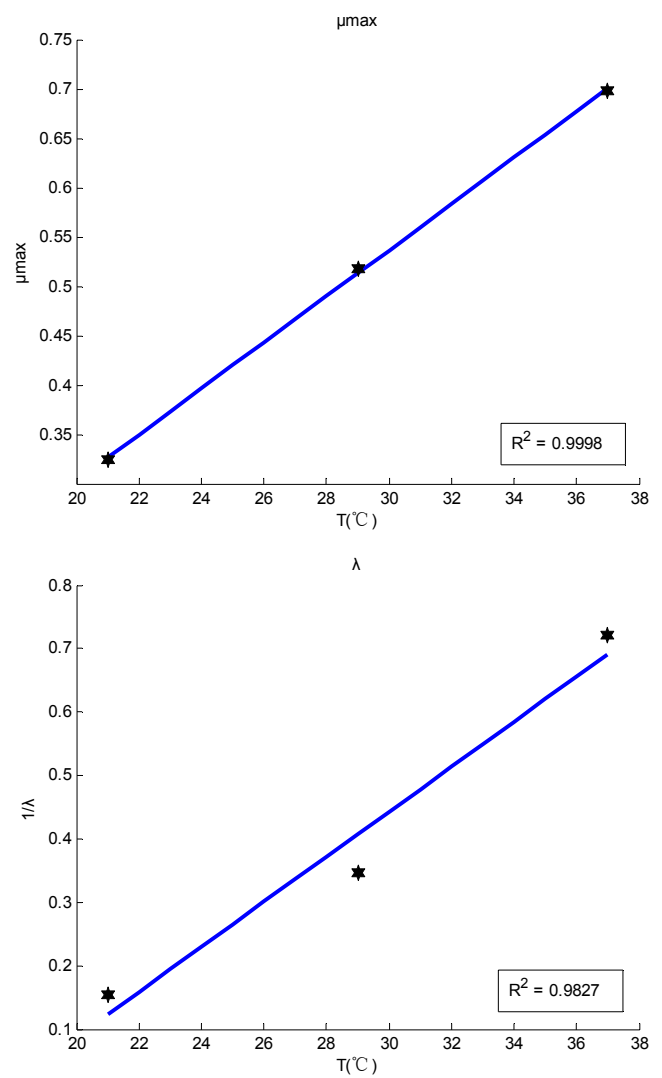

Fig.3. Relationship of temperature with $\mu$ max and Lag time

As can be learned from Fig. 3, there was a good linear relationship between temperature and $\mu_{\max }$ and $1 / \lambda$. The Belehradek equation between temperature and $1 / \lambda$ and $\mu_{\max }$ :

$$
\begin{aligned}
& \sqrt{\mu_{\max }}=0.0355(T-7.0360) \\
& \sqrt{1 / \lambda}=0.0355(T-17.5214)
\end{aligned}
$$

\section{The validation of the model}

The forecast and the measured growth curve of Escherichia coli 1.1187 in the sterile lettuce juices under $22^{\circ} \mathrm{C}$ and $30^{\circ} \mathrm{C}$ conditions are shown in Fig. 4 .
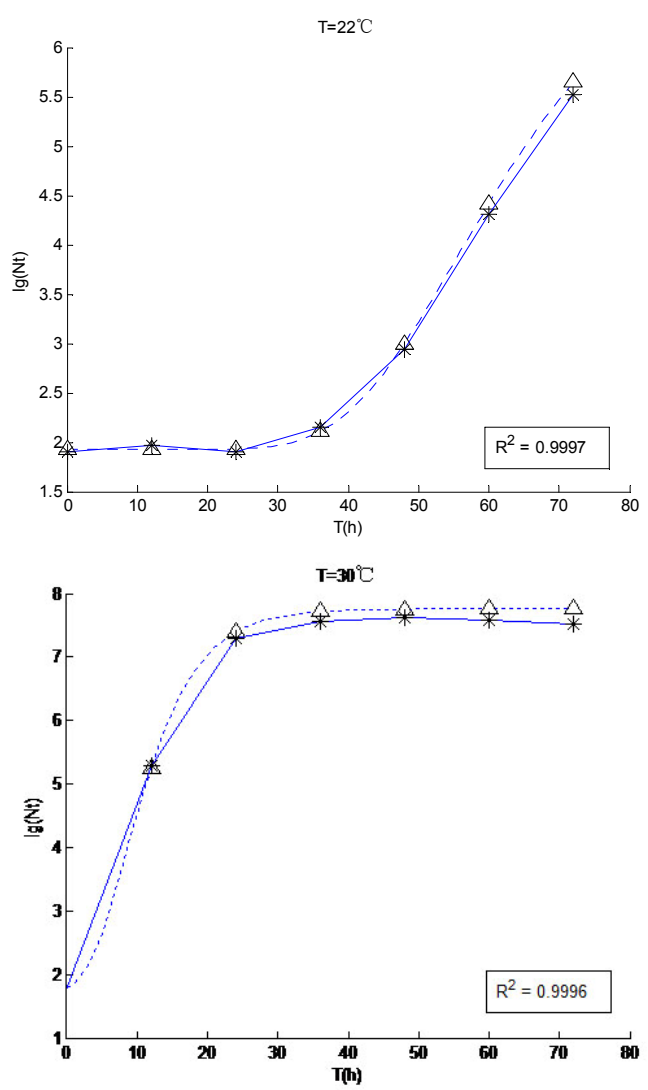

Fig.4. Predicted $(\triangle)$ and observed(*) growth curves of Escherichia coli 1.1187 in Sterile lettuce juice at $22^{\circ} \mathrm{C}$ and $30^{\circ} \mathrm{C}$

\section{IV.DISCUSSION}

Pathogenic microorganisms in food in the throughout exposure assessment is dynamic, if you can not grasp the dynamic changes of pathogenic microorganisms, then the quantitative assessment of the hazards is almost impossible. But the model of predictive microbiology is just the most powerful tool to solve this problem. The predictive model which is established by the experiment describes the growth changes of Escherichia coli 1.1187 in different temperatures, and if combined with other environmental factors, you can predict the growth changes of Escherichia coli 1.1187 in the entire exposure process, and ultimately, to estimate the levels of pathogenic bacteria in various stages and when lettuce is eaten. Then input this result into the dose-response model, can be concluded that the distribution of Escherichia coli 1.1187 in fresh-cut lettuce of consumption and the dosage of consumers, and bring these quantitative and qualitative information into together by risk characterization, can be concluded a safety evaluation of microorganisms in fresh-cut lettuce ${ }^{[8]}$.

E.coli 1.1187 used in this paper is one strain of E. coli K12. E. coli K12 strains (Escherichia coli K-12) was separated from the convalescent diphtheria patient's body at Stanford University in 1922, widely used in various studies, the biosphere, a chromosome map is the most detailed grasp 
biological, widely used to replace pathogenic $E$. coli-related research as a common type strain ${ }^{[9]}$.

This study used the modified Gompertz equation. At $4^{\circ} \mathrm{C}$ $11^{\circ} \mathrm{C}, 19^{\circ} \mathrm{C}, 27^{\circ} \mathrm{C}$ and $35^{\circ} \mathrm{C}$ storage conditions, the growth of $E$. coli 1.1187 in fresh-cut lettuce conditions, temperature return to the square of the correlation coefficient $\left(\mathrm{R}^{2}\right)$ as shown in Table I all above 0.99 , indicating that the equation can describe E. coli 1.1187 dynamic growth rhythm in the fresh-cut lettuce. However, at $4^{\circ} \mathrm{C}$ E. coli 1.1187 basically no growth, so the equation does not apply to $4^{\circ} \mathrm{C}$.

The study confirmed that the square root of the model was one of the best model for description of temperature on microbial growth affect. Thus, this experiment and the influence of different temperatures on the square root of the model will be described by a linear regression curve, $\mathrm{R}^{2}$, respectively,was 0.9998 and 0.9827 , showed a good linear relationship, so as to create the second model has a good reliable sex. Wherein according to (7) and (8) to obtain E.coli 1.1187 low growth temperature and optimum growth temperature of $7.03^{\circ} \mathrm{C}$ and $17.52^{\circ} \mathrm{C}$ respectively.

Sterile raw juice stored under conditions at $22^{\circ} \mathrm{C}$ and $30^{\circ} \mathrm{C}$ in the growth of $E$. coli 1.1187 measured and predicted values is verified by comparing the model, the Bias factor $\left(B_{f}\right)$ was $0.998,0.990$, the Accuracy factor $\left(A_{f}\right)$ was 1.0037 , 1.0022 , the Bias factor $\left(B_{f}\right)$ is used to check the predictive value of the amplitude fluctuations and the Accuracy factor $\left(A_{f}\right)$ is used to measure between the predicted and measured values, the two values between 0.90-1.05 verified constant temperature of the validity of the model. The $\mathrm{R}^{2}$ were 0.9997 and 0.9996 at $22^{\circ} \mathrm{C}$ and $30^{\circ} \mathrm{C}$, indicating a good correlation.

In summary, we analyzed the growth of Escherichia coli 1.1187 in sterile raw juiceunder different temperature conditions; we developed and validated a predictive model to predict Escherichia coli 1.1187 growth in fresh-cut lettuce over storage time based on Matlab7.0. The established predictive model can effectively predict Escherichia coli 1.1187 dynamic growth rhythm in fresh-cut lettuce over storage time.

\section{ACKNOWLEDGEMENTS}

This research work was supported in part by a grant from Food Industry and Supply Chain Management Studies:Co-operative Research Project of Harper Adams University and Beijing University of Agriculture, and a National“863”Program Grant (No. 2012AA101606-05).

\section{REFERENCES}

[1] Liu xiuying, Hu yixiu, "Global food borne disease status," Foreign medical(Volume of health),2003,vol.30,no.4,pp.199-204.

[2] MCMEEKIN T A, OLLEY J, RATKOWSKY D A, et al. "Predictive microbiology: towards the interface and beyond," International Journal of Food Microbiology, 2002, vol.73, pp.395-407.

[3] MCMEEKIN T A,BARANYI J,BOWMAN J, et al. "Information systems in food safety management," International Journal of Food Microbiology, 2006,vol.113,pp.181-194.

[4] Kristel Bernaerts, Karina J. Versyck, Jan F. Van Impe, "On the design of optimal dynamic experiments for parameter estimation of a
Ratkowsky-type growth kinetics at suboptimal temperatures," International Journal of Food Microbiology, 2000,vol.54, pp.27-38.

[5] ISABELLE L,ANDRE L, "Quantitative prediction of microbial behavior during food processing using an integrated modeling approach: a review," Int J Refrig, 2006,vol.29,pp.968-984.

[6] ROSS T, "Indices for performance evaluation of predictive models in food microbiology," Journal of Application Bacteriology, 1996, vol.81,pp.501-508.

[7] RATKOWSKY D A, OLLEY J, MCMEEKIN $T$ A, et al. "Relationship between temperature and growth rate of bacterial cultures," Journal of Bacterioloy, 1982, vol.149, no.1,pp. 1-5.

[8] MCMEEKIN T A, "Predictive microbiology: quantitative science delivering quantifiable benefits to the meat industry and other food industries," Meat Science, 2007,vol.77,pp.17-27.

[9] Sean D. Hooper, Otto G. Berg, "Gene import or deletion: A study of the different genes in Escherichia coli strains K12 and O157:H7," Journal of Molecular Evolution,2002,vol.55,pp.734-744. 